\title{
Pain-to-hospital times, cardiovascular risk factors, and early intrahospital mortality in patients with acute myocardial infarction
}

This article was published in the following Dove Press journal:

Therapeutics and Clinical Risk Management

II February 2015

Number of times this article has been viewed

\author{
Eliana Brkovićl \\ Katarina Novak ${ }^{2,3}$ \\ Livia Puljak ${ }^{3}$ \\ 'Department of Psychiatry, \\ ${ }^{2}$ Department of Internal Medicine, \\ Division of Cardiology, ${ }^{3}$ Laboratory \\ for Pain Research, University of Split \\ School of Medicine, Split, Croatia
}

Background: The aim of the study was to analyze the most recent trends in myocardial infarction (MI) care, the number of patients treated for MI and their outcomes, cardiovascular disease risk factors, and pain-to-hospital times in MI patients.

Subjects and methods: For 778 patients treated for acute MI at the Coronary Care Unit (CCU) of University Hospital Split, Croatia the following data were acquired: outcome during hospitalization (survived, deceased), cardiovascular risk factors (hypertension, diabetes, dyslipidemia, previous MI, smoking), and pain-to-CCU time.

Results: Among 778 patients treated for acute MI, there were 291 (37\%) women and 487 (63\%) men. Forty-five patients $(6 \%)$ died during hospitalization, mostly due to cardiogenic shock. An association was found between early intrahospital mortality and the following risk factors: age $>70$ years, female sex, previous MI, and smoking. Median pain-to-call time was 2 hours, and median time from the onset of pain to arrival into the CCU was 4 hours. There were 59 (7.6\%) patients admitted to the CCU within recommended 90 minutes. Diabetic comorbidity was not associated with early death or with longer time from pain to emergency calls.

Conclusion: Some of the risk factors associated with adverse outcomes in MI are modifiable. Prehospital delay of 4 hours observed in patients who suffered an MI is too long, and more effort should be devoted to investments in health care and education of the general public regarding chest pain symptoms.

Keywords: prehospital delay, ischemic heart disease

\section{Introduction}

Ischemic heart disease is a spectrum of diseases that remains the leading cause of death worldwide. ${ }^{1}$ It is also the most common cause of death in Croatia, in both men and women, causing one fifth of all deaths. ${ }^{2}$ Hospitalization trends in myocardial infarction (MI) in the Croatian region of Central Dalmatia have been reported in several publications during the last few decades. The number of hospitalized patients with MI significantly increased during the peak years of war in Croatia, including a significant increase in the incidence in men younger than 45 and with smoking as the most important risk factor. Data on MI between 1989 and 1997 showed the highest mortality in patients older than 45 , with hypercholesterolemia and high blood pressure. ${ }^{3-5}$ Between 1999 and 2005 the number of patients hospitalized due to MI in Central Dalmatia did not show increasing trends. ${ }^{6}$

However, it has been shown that the pain-to-hospital times for MI patients from Central Dalmatia is too long compared to recommended standards. ${ }^{6}$ Since 2005 , percutaneous coronary intervention (PCI) is available as a hospital treatment in Central
Correspondence: Livia Puljak

Laboratory for Pain Research, University of Split School of Medicine, Soltanska 2,

Split 21000, Croatia

Tel +38521557807

Fax +385 21 557811

Email livia@mefst.hr 
Dalmatia. ${ }^{6}$ However, the effectiveness of this treatment depends on administration of thrombolysis shortly after the onset of symptoms, and the main cause of delay in patients reaching the hospital after $\mathrm{MI}$ is the time it takes the patient to decide that their symptoms require medical attention. ${ }^{7}$ Although it is recommended that the pain-to-hospital time should be less than 90 minutes, urban patients hospitalized for MI in Central Dalmatia needed a median of 2 hours to call the emergency after the onset of pain, and the total prehospital delay was 4.3 hours. ${ }^{6}$ Together with recent findings that only $38 \%$ of patients with acute MI (AMI) from Central Dalmatia are hospitalized, it is clear that there is a lot of room for improvement of MI care in this geographic area.

The established cardiovascular disease (CVD) risk factors, including high blood pressure, adverse blood lipid profile, diabetes mellitus, obesity, and smoking have been addressed in recommendations and guidelines beginning a half-century or more ago. These commonly recognized risk factors jointly account for $80 \%$ of the burden of ischemic heart disease. ${ }^{8}$ In 2012, the CroHort study revealed trends in behavioral and biomedical CVD risk factors in Croatia, indicating that smoking and alcohol consumption in men decreased significantly compared to 2008, while alcohol consumption and obesity in women, as well as hypertension in both sexes, increased significantly. ${ }^{9}$ Negative trends reported in this study show that more attention should be devoted to CVD risk factors and CVD prevention.

The aim of the study was to analyze the most recent trends in MI care, the number of patients treated for MI and their outcomes, CVD risk factors, and pain-to-hospital times in MI patients.

\section{Subjects and methods Study design and setting}

The study was conducted in Central Dalmatia, Croatia, over a 2-year period, from January 1, 2010 to December 31, 2011, at University Hospital Split. Data were collected from medical histories of patients treated for AMI at the Department of Internal Medicine, Division of Cardiology, Coronary Care Unit (CCU) of the University Hospital Split in Split, Croatia.

Data collection was approved by the University Hospital Split Ethics Committee, and the need for informed consent was waived due to anonymous data collection. The study was conducted according to the principles set by the Declaration of Helsinki.

\section{Participants}

The inclusion criteria were adult patients of both sexes with chest pain and confirmed clinical, electrocardiographic, and biochemical signs of AMI according to the criteria of the European Society of Cardiology, ${ }^{10,11}$ hospitalized at the CCU of University Hospital Split during the studied 2-year period.

\section{Procedures}

Each patient admitted to the CCU with suspected AMI was evaluated. The diagnosis of MI was based on a thorough medical history, a standard 12-channel electrocardiogram, and the following laboratory findings: creatine kinase (CK), $\mathrm{MB}$ fraction of $\mathrm{CK}$, alanine aminotransferase, aspartate aminotransferase, and lactate dehydrogenase.

Troponin is also used in the analyzed hospital for diagnosing AMI, but in this study, it was not one of the studied variables because patients were coming from the entire county. Many remote biochemical laboratories do not perform the troponin test; therefore, those patients arrive at the hospital without initial troponin values. Since troponin values depend on the time of measurement that has passed from the onset of pain, and many patients came late after the onset of pain, $\mathrm{CK}$ and $\mathrm{CK}-\mathrm{MB}$ were used because all of the laboratories in the county measure those values.

The following variables were recorded for each patient: age, sex, place of residence, and time of the onset of pain. Considering the place of residence, patients were divided into three groups:

1. patients from Split and surrounding areas up to $15 \mathrm{~km}$ from the city of Split;

2. patients from Split-Dalmatia county located more than $15 \mathrm{~km}$ from the city of Split;

3. residents of central Dalmatian islands of Brač, Šolta, Drvenik, Drvenik Mali, Hvar, Vis, Lastovo, and Korčula.

Specific cardiovascular and infarction-related recorded information included the region of infarction; arrhythmias; heart failure; treatment outcome during hospitalization period, that on average lasted 8 days (alive or deceased); and for the deceased, time and cause of death (cardiogenic shock, electromechanical dissociation, ventricular fibrillation, asystole). Cardiovascular risk factors examined in each patient were hypertension, smoking, diabetes, dyslipidemia, history of MI, and stroke. Treatment was categorized into three groups including PCI, fibrinolytic therapy, and conservative treatment.

For determining values of risk factors, guidelines of the European Society of Cardiology were used. For dyslipidemia, irregular total cholesterol (after 12 hours fasting) was defined as values $>5 \mathrm{mmol} / \mathrm{L}$, high-density lipoprotein $<1 \mathrm{mmol} / \mathrm{L}$ (men) and $<1.2 \mathrm{mmol} / \mathrm{L}$ (women), and low-density lipoprotein cholesterol $>3 \mathrm{mmol} / \mathrm{L}$. For diabetes, fasting 
values of $\mathrm{HbA}_{1 \mathrm{c}}>6.5$, fasting plasma glucose $>6 \mathrm{mmol} / \mathrm{L}$, and glucose after meal $>11.1 \mathrm{mmol} / \mathrm{L}$. For hypertension, values of arterial blood pressure $>140 / 90 \mathrm{mmHg}$ during rest in a seated position.

To calculate prehospital delay, the following data were obtained from patients or accompanying persons: time of onset of pain, time from the onset of pain to the emergency call (pain-to-call time), time from the call to arrival of an ambulance (call-to-ambulance), time from the arrival of ambulance to admission to an emergency department (ambulance-to-door), and time from admission to an emergency department to admission to a CCU (door-to-CCU).

\section{Statistical analysis}

Anonymized patient data were entered into an electronic database and analyzed using Statistica 7 software (StatSoft, Tulsa, OK, USA). Data were analyzed using descriptive statistics. Variables with a normal distribution were presented as mean and standard deviation. The data that were not normally distributed were presented as median and interquartile range (IQR). The correlation between variables was tested using the Mann-Whitney $U$ and $\chi^{2}$ tests. Logistic regression analysis was performed to determine the association between cardiovascular risk factors and patient outcome during hospitalization (alive or deceased).

\section{Results}

In the CCU of University Hospital Split, 2,704 patients were treated for various cardiovascular conditions during the study period. There were 778 (29\%) patients treated for AMI, 401 patients in year 2010, and 377 in 2011. There were 30\% (230/778) of patients with non-ST-segment AMI. The median (IQR) age of patients was 67 (58-77) years. Men were aged 65 (57-75) and women 71 (60-81) years. The median (IQR) time of day when patients first experienced AMI-related pain was 10 am (6 am - 5 pm). Most of the patients with AMI came from the vicinity of Split ( $\mathrm{N}=456 ; 58 \%)$, followed by those from Split ( $\mathrm{N}=246 ; 32 \%)$, while the lowest number of patients was transported from the islands $(\mathrm{N}=76 ; 10 \%)$.

Most patients were treated with conservative therapy $(\mathrm{N}=526 ; 68 \%)$ and PCI $(\mathrm{N}=231 ; 30 \%)$ while few patients were treated with fibrinolytic therapy $(\mathrm{N}=21 ; 2 \%)$. At the end of the hospitalization period immediately after AMI, $733(94 \%)$ patients were alive while 45 (6\%) were deceased. The most common cause of death was cardiogenic shock $(\mathrm{N}=23 ; 52 \%)$, followed by electromechanical dissociation $(\mathrm{N}=10 ; 22 \%)$, asystole $(\mathrm{N}=10 ; 22 \%)$, and ventricular fibrillation $(\mathrm{N}=2 ; 4 \%)$.

Among the patients who survived the hospitalization period, AMI was most often located in the anterior region $(\mathrm{N}=24 ; 34 \%)$ while anterior or inferior infarction area was found in equal numbers among deceased (each $\mathrm{N}=15 ; 33 \%$ ). The majority of patients did not have cardiac arrhythmias after AMI (N=610; 78\%). In patients with cardiac arrhythmia, atrial fibrillation was the most common; it was observed in $11 \%$ of patients who survived and those who deceased during the hospitalization period. Heart failure was 2.7 times more frequent in patients of MI who died during the hospitalization immediately after $\mathrm{MI}(\mathrm{N}=35 ; 78 \%)$ compared with the group of patients who survived $(\mathrm{N}=198 ; 27 \%)$ until the end of the hospitalization for AMI $\left(\chi^{2}=52, P<0.001\right)$.

In the group of deceased AMI patients, there were more women compared to the group of patients who survived the period of hospitalization, but this difference was not significant. Among the deceased, there were twice as many respondents aged $>70$ years (Table 1 ). After exploring association of a number of cardiovascular risk factors with the outcome (alive, deceased) during hospitalization immediately after AMI, statistically significant association was not found between the outcome and high

Table I Cardiovascular risk factors among patients with acute myocardial infarction, according to the outcome (alive, deceased) during hospitalization

\begin{tabular}{|c|c|c|c|c|c|c|}
\hline Category & Subcategory & $\begin{array}{l}\text { Survived } \\
(\mathbf{N}=733)\end{array}$ & $\begin{array}{l}\text { Deceased } \\
(\mathrm{N}=45)\end{array}$ & $P^{*}$ & OR (95\% CI) & $\boldsymbol{P}^{\dagger}$ \\
\hline \multirow[t]{2}{*}{ Sex } & Women & $268(37)$ & $23(5 \mathrm{I})$ & 0.072 & $1.8(0.99-3.32)$ & 0.053 \\
\hline & Men & $465(63)$ & $22(49)$ & & & \\
\hline \multirow[t]{2}{*}{ Age (years) } & $\leq 70$ & $440(60)$ & $9(20)$ & $<0.001$ & $6(2.8-12.7)$ & $<0.001$ \\
\hline & $>70$ & $292(40)$ & $19(80)$ & & & \\
\hline Hypertension & & $612(83)$ & $37(82)$ & 0.824 & I.I (0.5-2.4) & 0.824 \\
\hline Diabetes & & $221(30)$ & $17(38)$ & 0.362 & $1.4(0.75-2.6)$ & 0.283 \\
\hline Smoking & & $240(33)$ & $6(13)$ & 0.011 & $3.2(1.3-7.6)$ & 0.010 \\
\hline Hypercholesterolemia & & $4 I I(56)$ & $23(5 \mathrm{I})$ & 0.620 & $1.2(0.67-2.2)$ & 0.516 \\
\hline Previous AMI & & $205(28)$ & $22(49)$ & 0.003 & $2.4(1.3-4.5)$ & 0.004 \\
\hline
\end{tabular}

Notes: *Represents $\chi^{2}$ test; ${ }^{\dagger}$ Represents logistic regression.

Abbreviations: AMI, acute myocardial infarction; $\mathrm{Cl}$, confidence interval; OR, odds ratio. 
blood pressure, diabetes, or elevated cholesterol. Among the deceased, there were 2.5 times less smokers than in the group of patients who survived the hospitalization period. Significantly more patients with a history of AMI were found among the deceased (Table 1).

Logistic regression was also used to analyze the basic risk. The dependent variable was "outcome", and predictors were sex, age, smoking, and history of AMI. The significant predictors of the outcome were only age and previous history of AMI (Table 1).

Sixty one percent of patients $(\mathrm{N}=473)$ called for acute medical help 1 hour after the onset of AMI symptoms. The longest recorded pain-to-call time was 21 hours. The majority of patients $(56 \%)$ were transported to the hospital 30 minutes within the arrival of the ambulance. Only $59(7.6 \%)$ patients were admitted to the CCU within the recommended 90 minutes. Most of the patients were admitted to CCU within 6 hours from the onset of pain while $50(6.4 \%)$ patients were admitted to CCU more than 12 hours after the onset of chest pain (Table 2).

Prehospital delay was longer for patients coming from mainland outside of Split and those from the islands (Table 3). There was no significant difference in the time of day when the pain occurred between survivors and deceased during hospitalization $(z=0.92, P=0.357)$. The pain-to-call time did not differ in patients who survived a period of hospitalization and those who died shortly after hospitalization $(z=0.546$, $P=0.585)$. Also, there were no significant differences in prehospital delay based on the outcome (Table 4).

Among the 238 patients who were suffering from diabetes, there were 235 patients with type 2 diabetes, and only three patients with diabetes type 1 . Among diabetic patients, there were more women than men. Diabetic patients were older than patients with AMI who did not have diabetes (Table 5).

Table 2 Time elapsed from onset of pain to admission to coronary care unit

\begin{tabular}{lll}
\hline Prehospital delay (hour) & Subcategory & N (\%) \\
\hline Pain-to-call & $\leq \mathrm{I}$ & $305(39)$ \\
& $>\mathrm{I}$ & $473(6 \mathrm{I})$ \\
Pain-to-CCU & $\leq 1.5$ & $59(7.6)$ \\
& $\mathrm{I} .6-3$ & $195(25)$ \\
& $3.1-6$ & $288(37)$ \\
& $6.1-12$ & $186(24)$ \\
Door-to-CCU & $>12$ & $50(6.4)$ \\
& $\leq 0.5$ & $406(52)$ \\
& $>0.5$ & $372(48)$ \\
\hline
\end{tabular}

Abbreviation: $\mathrm{CCU}$, coronary care unit.
Comparing the patients with AMI who were suffering from diabetes and those who did not suffer from diabetes, there was no statistically significant difference in the time of day when the pain due to MI appeared $(z=0.090, P=0.928)$. A significant difference between diabetic and nondiabetic patients has not been established for any of the analyzed components of prehospital delay (Table 6).

\section{Discussion}

Although the prevalence of hospitalizations remained unchanged, pain-to-hospital times and early intrahospital survival of patients with AMI in Central Dalmatia have improved compared to earlier years. The annual number of AMI patients hospitalized in Central Dalmatia ranged from 308 to 467 between 1989 and $2005^{4,6}$ while this study indicated that it was 401 and 377 in years 2010 and 2011, respectively. Intrahospital survival of AMI patients was $81.3 \%$ in 1999 , significantly less than $91.2 \%$ in $2005,{ }^{6}$ and rising to $94 \%$ in the present study. These data are novel because they offer insights into recent trends about CVD risk factors and prehospital delay related to AMI in a transitional country setting.

At the beginning of 2005, a regular 24-hour PCI service was introduced at the University Hospital Split. ${ }^{6}$ One third of the patients in this study were treated with PCI. Reduction of early mortality from AMI is attributed to the timely intensive adoption of advanced forms of acute health care, including improved therapeutic interventions and better logistics in the search for patients for whom advanced therapy may be helpful. ${ }^{12}$ Adherence to practice guidelines improved care of patients with AMI and was associated with significant reductions in in-hospital mortality rates. The temporal improvements in acute therapies may account for up to $37 \%$ of the annual decline in risk for in-hospital AMI mortality. ${ }^{13}$

Most of the patients in this study were treated with conservative therapy due to a late arrival of patients into the hospital. Reperfusion treatment (whether PCI or fibrinolysis) is most successful when performed within the 1st hour from the onset of pain, but in the studied cohort only $5.7 \%$ of patients arrived at the hospital within 90 minutes from the onset of pain.

AMI case-fatality rate has been suggested as a good measure of the quality of acute care, because it reflects processes such as effective medical interventions. The majority of countries recorded significant reductions in case-fatality rates for AMI between 2000 and 2009. Decline in the in-hospital AMI mortality reflects advances in treatment such as the increased rates and timelines of reperfusion therapy. ${ }^{14,15}$ 
Table 3 Time elapsed from onset of pain to admission to coronary care unit by the patients' residence

\begin{tabular}{|c|c|c|c|}
\hline \multirow[t]{2}{*}{ Prehospital delay (hour)* } & \multicolumn{3}{|l|}{ Residence } \\
\hline & $\leq 15 \mathrm{~km}$ from Split & > I5 km from Split & Islands \\
\hline Pain-to-call & $2.0(0.5-4.0)$ & $2.0(0.7-5.0)$ & $2.0(0.7-4.0)$ \\
\hline Call-to-ambulance & $0.5(0.3-0.8)$ & $0.5(0.3-0.8)$ & $0.6(0.5-1.0)$ \\
\hline Ambulance-to-door & $0.6(0.4-1.0)$ & $0.6(0.4-\mid .2)$ & $1.0(0.5-1.7)$ \\
\hline Door-to-CCU & $0.5(0.3-0.9)$ & $0.5(0.3-1.0)$ & $0.7(0.4-0.9)$ \\
\hline
\end{tabular}

Note: $*$ Times are expressed as median (interquartile range).

Abbreviation: $\mathrm{CCU}$, coronary care unit.

Age, smoking, and history of MI were significantly associated with early survival of patients. There were more women among the deceased compared to those who survived until discharge from the hospital. A previous study in the same setting also found a higher percentage of women among the deceased. ${ }^{4}$ Women in this study were older than men.

Age is an important factor of sex-based differences in the presentation of MI, and women are older than men when presenting with acute coronary syndrome. ${ }^{16}$ There is a surge of female coronary heart disease morbidity after age 45 , and their case fatality rate from coronary attacks exceeds the male rate. A number of studies support a biological mechanism of sex-based differences in clinical presentation, including the effects of age, estrogen, and different patterns of atherosclerosis. ${ }^{16}$ Factors contributing to the outcomes of AMI in women are comorbidities and reduced compensatory capacity of the remaining myocardial tissue in older age. ${ }^{17,18}$ Women who suffer heart attacks have more cardiovascular risk factors. Further research is needed to enhance the current understanding of underlying pathophysiology that may help create potentially sex-tailored health messages to the general public, with resultant improvements in the care and survival of women. ${ }^{16}$

While in developed countries the impact of cardiovascular risk factors is reduced through better control of blood pressure, decreased fat intake, increased physical activity, and reduced smoking, ${ }^{19}$ in countries in transition, there is an increased influence of risk factors, including increased stress, air pollution, and lack of prevention of harmful factors. ${ }^{1,19}$ The importance of lifestyle, preventive activities, and reduction of cardiovascular risk factors has been shown in the study of a Spanish region with coronary disease inframortality. In 32 Spanish towns the ischemic heart disease mortality was half the national rate and four times lower than the European Union rate. ${ }^{20}$ Negative trends related to alcohol consumption, obesity, and hypertension in the Croatian population should be a target of elaborate public health activities. ${ }^{9}$

There are patient and health care system characteristics that are important for CVD prevention. Relevant patient characteristics are socioeconomic status and age, indicating that there is a specific subset of patients that needs more attention. For example, very high prevalence of conventional risk factors was found in patients with acute coronary syndrome. ${ }^{21}$

Health care-related factors important for CVD prevention are information system of the practice, availability of data in medical records, and continuing medical education on CVD. ${ }^{22}$

A recent analysis of waiting lists in CVDs revealed time delay in diagnostic and therapeutic phases and high variance in temporal gaps between them. Therefore, it has been recommended to invest more financial resources and include more physicians and more instruments able to earlier detect diseases and provide early treatment. ${ }^{23}$

An important factor in shortening ischemic time and patient outcomes in AMI involves integrated efforts to

Table 4 Total time elapsed from onset of pain to admission to coronary care unit by the outcome during hospitalization (alive/ deceased)

\begin{tabular}{llll}
\hline Prehospital delay (hour)* & Survived $(\mathbf{N}=\mathbf{7 3 3})$ & Deceased $(\mathbf{N}=\mathbf{4 5})$ & $\boldsymbol{P}^{* *}$ \\
\hline Pain-to-call & $2(0.1-2 \mathrm{I})$ & $1.8(0.1-10.8)$ & 0.585 \\
Pain-to-ambulance & $2.5(0.2-22)$ & $2.3(0.5-11.1)$ & $0.67 \mathrm{I}$ \\
Pain-to-door & $3.4(0.4-22.5)$ & $3.0(0.9-13)$ & 0.656 \\
Pain-to-CCU & $4(0.8-23)$ & $4(I-14)$ & 0.178 \\
\hline
\end{tabular}

Notes: *Times are expressed as median (interquartile range); **Represents Mann-Whitney U-test.

Abbreviation: $\mathrm{CCU}$, coronary care unit. 
Table 5 Sex and age of patients with acute myocardial infarction in relation to diabetes

\begin{tabular}{lllll}
\hline Categories & Subcategories & All patients & $\begin{array}{l}\text { Nondiabetic } \\
(\mathbf{N}=\mathbf{5 4 0 )}\end{array}$ & $\begin{array}{l}\text { Diabetic } \\
(\mathbf{N}=\mathbf{2 3 8})\end{array}$ \\
\hline Sex, N (\%) & & & $192(36)$ & $99(42)$ \\
& Female & $291(37.4)$ & $348(64)$ & $139(58)$ \\
Age, years (\%) & Male & $487(62.6)$ & $339(63)$ & $110(46)$ \\
& $\leq 70$ & $449(58)$ & $201(37)$ & $127(54)$ \\
\hline
\end{tabular}

shorten the time delay in successive stages of patients' decision to call emergency service, transfer to the hospital and hospital management. ${ }^{24}$ Previous data from Central Dalmatia showed that the median prehospital delay of AMI patients in 2005 was 4.3 hours, and $5.7 \%$ of patients were admitted to CCU within recommended 90 minutes. These results were already significantly shorter compared with data from earlier studies in this geographic area. ${ }^{6,25}$ Median prehospital delay in Central Dalmatia was 5.5 hours in $1999^{6}$ while it averaged $14.8 \pm 11.6$ hours between the years 1981 and $1987 .{ }^{25}$ In years 2010 and 2011, median prehospital delay was 4 hours, and $7.6 \%$ of patients were admitted to CCU within 90 minutes. We also found that there was no correlation between painto-call time and either sex or age in the same setting. ${ }^{6}$

Although reduced, prehospital delay of AMI patients is still too long, keeping in mind the guidelines regarding the optimal period for administering reperfusion and PCI. Compared with other large international studies, pain-to-hospital times of AMI patients in Central Dalmatia are significantly delayed. ${ }^{26-28}$ In Split-Dalmatia county, regional geography and transportation issues affect patients who come from the mainland outside of the city of Split and those from the islands. The mainland region is mountainous, with many remote rural areas served by a suboptimal road system. The island population relies on infrequent commercial ferries or police boats and army helicopters in emergency situations, which are subject to administrative approval procedures. Improving cardiac emergency care in these areas requires consideration of those factors as well. ${ }^{6}$

The only part of the preshopital delay that does not depend upon the health care system, but is entirely dependant upon patients, is the pain-to-call time. Median pain-to-call time was 2 hours in 2005, and it remained unchanged in 2010-2011.6 This means that residents of Central Dalmatia wait too long before calling for help, losing precious time that is necessary for optimal reperfusion. Improvements in the health care system are not followed with increased awareness of patients about symptoms of AMI. A recent study showed that as much as half of coronary patients are not instructed on how to respond to symptoms of a heart attack. ${ }^{29}$

A useful intervention would be the introduction of "care manager" nurses, with the purpose of creating a strong collaborative team between health care workers and patients and empowering patients to take a more active role in caring for their health. ${ }^{30}$

It has been suggested in the literature that diabetes is one of the factors associated with a longer prehospital delay in AMI patients. However, contradictory findings about this issue have been reported..$^{31,32}$ In our study, no significant difference was found in prehospital delay between patients with or without diabetes. However, this study included patients suffering predominantly from type 2 diabetes, with only $1 \%$ of patients in the sample suffering from type 1 diabetes. There is a possibility that type 1 diabetes contributes more to the extension of prehospital delay than type 2 diabetes, which could explain why the association between diabetes and prehospital delay of patients with AMI was not found in this study.

A limitation of this research is its retrospective nature of the study design. Confounding errors and bias are more common in retrospective studies than in prospective studies. Additionally, this kind of study design provides only a certain

Table 6 Time of occurrence of acute myocardial infarction and prehospital delay in relation to diabetes

\begin{tabular}{|c|c|c|c|}
\hline Time (hour)* & $\begin{array}{l}\text { Nondiabetic } \\
(\mathrm{N}=540)\end{array}$ & $\begin{array}{l}\text { Diabetic } \\
(\mathrm{N}=\mathbf{2 3 8})\end{array}$ & $P * *$ \\
\hline Time of day when the AMI occurred & $10(0-24)$ & $10(0-23.4)$ & 0.928 \\
\hline Pain-to-call & $1.9(0.1-21)$ & $2(0.1-15)$ & 0.321 \\
\hline Pain-to-ambulance & $2.35(0.2-22)$ & $2.55(0.3-15.3)$ & 0.219 \\
\hline Pain-to-door & $3.3(0.4-22.5)$ & $3.7(0.6-20)$ & 0.456 \\
\hline Pain-to-CCU & $4(I-23)$ & $4.2(0.8-2 I)$ & 0.295 \\
\hline
\end{tabular}

Notes: $*$ Times are expressed as median (interquartile range); ${ }^{* *}$ Represents Mann-Whitney U-test.

Abbreviations: AMI, acute myocardial infarction; $\mathrm{CCU}$, coronary care unit. 
amount of information. In this study there were 29 patients who called for help more than 10 hours after the onset of pain, and our data cannot offer insight into the reasons why these patients decided to call for help after such a long delay. Future studies should take this limitation into account.

In conclusion, although the prevalence of hospitalizations due to AMI in Central Dalmatia remains the same, it is encouraging that the management of AMI patients is improving, which is demonstrated through shorter prehospital delay and lower early mortality compared to previous years. However, prehospital delay of 4 hours is still too long, and more effort should be devoted to this segment of health care and the education of the general public on chest pain symptoms.

\section{Acknowledgment}

We are grateful to Ms Dora Sapunar for language editing.

\section{Author contributions}

EB: data collection, interpretation of data, writing the paper, approval of the final version; KN: study design, data analyses, interpretation of data, revision of the drafted paper, approval of the final version; LP: study design, data analyses, interpretation of data, writing the paper, approval of the final version.

\section{Disclosure}

This work received no funding. The authors report no conflicts of interest in this work.

\section{References}

1. Sans S, Kesteloot H, Kromhout D. The burden of cardiovascular diseases mortality in Europe. Task Force of the European Society of Cardiology on Cardiovascular Mortality and Morbidity Statistics in Europe. Eur Heart J. 1997;18(12):1231-1248.

2. Characteristics of population health status and healthcare in the year 2001. Split, Croatia: Public Health Institute of the Split-Dalmatia County; 2003:212.

3. Mirić D, Eterović D, Giunio L, et al. Triggers of acute myocardial infarction regarding its site. Int J Cardiol. 1997;60(1):67-71.

4. Mirić D, Rumboldt Z, Rumboldt M, et al. [Characteristics of patients with acute myocardial infarction treated in Split 1982-1992]. Lijec Vjesn. 1994;116(3-4):79-82. Croatian.

5. Mirić D, Giunio L, Bozić I, Fabijanić D, Martinović D, Culić V. Trends in myocardial infarction in Middle Dalmatia during the war in Croatia. Mil Med. 2001;166(5):419-421.

6. Novak K, Aljinovic J, Kostic S, et al. Pain to hospital times after myocardial infarction in patients from Dalmatian mainland and islands, southern Croatia. Croat Med J. 2010;51(5):423-431.

7. Horne R, James D, Petrie K, Weinman J, Vincent R. Patients' interpretation of symptoms as a cause of delay in reaching hospital during acute myocardial infarction. Heart. 2000;83(4):388-393.

8. Labarthe DR, Dunbar SB. Global cardiovascular health promotion and disease prevention: 2011 and beyond. Circulation. 2012;125(21): 2667-2676.
9. Poljicanin T, Dzakula A, Milanović SM, Sekerija M, Ivanković D, Vuletic S. The changing pattern of cardiovascular risk factors: the CroHort study. Coll Antropol. 2012;36(Suppl 1):9-13.

10. Acute myocardial infarction: pre-hospital and in-hospital management. The Task Force on the Management of Acute Myocardial Infarction of the European Society of Cardiology. Eur Heart J. 1996;17(1): 43-63.

11. Van de Werf F, Ardissino D, Betriu A, et al; Task Force of the Management of Acute Myocardial Infarction of the European Society of Cardiology. Management of acute myocardial infarction in patients presenting with ST-segment elevation. The Task Force on the Management of Acute Myocardial Infarction of the European Society of Cardiology. Eur Heart J. 2003;24(1):28-66.

12. Kuch B, von Scheidt W, Kling B, Ehmann A, Greschik C, Meisinger C. Are there options to prevent early occurring deaths in acute myocardial infarction: prospective evaluation of all $<24 \mathrm{~h}$ in-hospital deaths, 2004-2006 - the MONICA/KORA Augsburg Infarction Registry. Cardiology. 2010;116(4):237-244.

13. Peterson ED, Shah BR, Parsons L, et al. Trends in quality of care for patients with acute myocardial infarction in the National Registry of Myocardial Infarction from 1990 to 2006. Am Heart J. 2008; 156(6): 1045-1055.

14. Fox KA, Steg PG, Eagle KA, et al; GRACE Investigators. Decline in rates of death and heart failure in acute coronary syndromes, 1999-2006. JAMA. 2007;297(17):1892-1900.

15. Tu JV, Nardi L, Fang J, Liu J, Khalid L, Johansen H; Canadian Cardiovascular Outcomes Research Team. National trends in rates of death and hospital admissions related to acute myocardial infarction, heart failure and stroke, 1994-2004. CMAJ. 2009;180(13):E118-E125.

16. Canto JG, Rogers WJ, Goldberg RJ, et al; NRMI Investigators. Association of age and sex with myocardial infarction symptom presentation and in-hospital mortality. JAMA. 2012;307(8):813-822.

17. Tofler GH, Stone PH, Muller JE, et al. Effects of gender and race on prognosis after myocardial infarction: adverse prognosis for women, particularly black women. J Am Coll Cardiol. 1987;9(3):473-482.

18. Bell DM, Nappi J. Myocardial infarction in women: a critical appraisal of gender differences in outcomes. Pharmacotherapy. 2000;20(9):1034-1044.

19. Gotto AM Jr. Lipid-lowering therapy for the primary prevention of coronary heart disease. J Am Coll Cardiol. 1999;33(7):2078-2082.

20. Medrano MJ, Boix R, Palmera A, Ramis R, Galán I, López-Abente G. Towns with extremely low mortality due to ischemic heart disease in Spain. BMC Public Health. 2012;12:174.

21. González-Pacheco H, Vargas-Barrón J, Vallejo M, et al. Prevalence of conventional risk factors and lipid profiles in patients with acute coronary syndrome and significant coronary disease. Ther Clin Risk Manag. 2014;10:815-823.

22. Petek D, Ferligoj A, Platinovsek R, Kersnik J. Predictors of the quality of cardiovascular prevention - a multilevel cross-sectional study. Croat Med J. 2011;52(6):718-727.

23. Ciccone MM, Aquilino A, Frasso G, et al. Waiting lists in coronary artery bypass graft patients and role of coronary angiography: the Apulian experience. Clinical Audit. 2013;2013(5):49-55.

24. Park YH, Kang GH, Song BG, et al. Factors related to prehospital time delay in acute ST-segment elevation myocardial infarction. J Korean Med Sci. 2012;27(8):864-869.

25. Mirić D, Rumboldt Z, Puljiz L, Ermakora R, Obad M, Bozić I. [The time interval from the onset of myocardial infarct to arrival in the coronary unit in the area of Split]. Lijec Vjesn. 1990;112(3-4):95-96. Croatian.

26. Goldberg RJ, Steg PG, Sadiq I, et al. Extent of, and factors associated with, delay to hospital presentation in patients with acute coronary disease (the GRACE registry). Am J Cardiol. 2002;89(7): 791-796.

27. Goldberg RJ, Yarzebski J, Lessard D, Gore JM. Decade-long trends and factors associated with time to hospital presentation in patients with acute myocardial infarction: the Worcester Heart Attack study. Arch Intern Med. 2000;160(21):3217-3223. 
28. Pitsavos C, Kourlaba G, Panagiotakos DB, Stefanadis C; GREECS Study Investigators. Factors associated with delay in seeking health care for hospitalized patients with acute coronary syndromes: the GREECS study. Hellenic J Cardiol. 2006;47(6):329-336.

29. Jankowski P, Bednarek A, Surowiec S, Loster M, Pająk A, KaweckaJaszcz K. Half of coronary patients are not instructed how to respond to symptoms of a heart attack. Cardiol J. 2011;18(6):668-674.

30. Ciccone MM, Aquilino A, Cortese F, et al. Feasibility and effectiveness of a disease and care management model in the primary health care system for patients with heart failure and diabetes (Project Leonardo). Vasc Health Risk Manag. 2010;6:297-305.
31. Vermeulen RP, Jaarsma T, Hanenburg FG, Nannenberg JW, Jessurun GA, Zijlstra F. Prehospital diagnosis in STEMI patients treated by primary PCI: the key to rapid reperfusion. Neth Heart J. 2008;16(1):5-9.

32. Banks AD, Dracup K. Factors associated with prolonged prehospital delay of African Americans with acute myocardial infarction. Am J Crit Care. 2006;15(2):149-157.

\section{Publish your work in this journal}

Therapeutics and Clinical Risk Management is an international, peerreviewed journal of clinical therapeutics and risk management, focusing on concise rapid reporting of clinical studies in all therapeutic areas, outcomes, safety, and programs for the effective, safe, and sustained use of medicines. This journal is indexed on PubMed Central, CAS,
EMBase, Scopus and the Elsevier Bibliographic databases. The manuscript management system is completely online and includes a very quick and fair peer-review system, which is all easy to use. Visit http://www.dovepress.com/testimonials.php to read real quotes from published authors.

Submit your manuscript here: http://www.dovepress.com/therapeutics-and-clinical-risk-management-journal 